\title{
FORMATION OF PERIODIC MULTIFILAMENTARY STRUCTURES BY USE OF HIGHLY ELLIPTIC LIGHT BEAMS
}

\author{
A. Dubietis, E. Kučinskas, G. Tamošauskas \\ Department of Quantum Electronics, Vilnius University, Saulètekio 9, LT-10222 Vilnius, Lithuania \\ E-mail: audrius.dubietis@ff.vu.lt
}

Received 8 January 2007

\begin{abstract}
Self-focusing and multiple filamentation of highly elliptic laser beams is studied experimentally in condensed media with Kerr nonlinearity (water and fused silica). We show that highly elliptic laser beam initially breaks up into one-dimensional array of filaments, producing deterministic and periodic patterns. At higher pump energies, the interplay between the neighbouring filaments gives rise to formation of complex two-dimensional spatial structures.
\end{abstract}

Keywords: self-focusing, multiple filaments, transverse instability

PACS: 42.65.Jx, 42.65.Re

Self-focusing is an ultimate manifestation of nonlinear response of a material to the intense light field and long ago has been shown to produce beam filamentation, spectral broadening, and coloured conical emission [1]. When the power of an incident laser beam exceeds that of the critical one for self-focusing, the laser beam eventually breaks up into multiple filaments. With the advent of femtosecond lasers, a better experimental access to filamentation phenomena has been acquired and it has set a new quality in understanding of underlying physical processes [2]. In this connection the multiple filamentation (MF) is a relevant and yet not completely understood phenomenon. In this regard, MF and white-light continuum generation with the high power femtosecond pulses has been observed in air and explained as an optically turbulent light guide resulting in random locations of intense filaments in space and time [3]. Current interest in controlled MF is motivated by the demand of precise localization of light filaments, crucial for many arising applications, such as broadband continuum generation, waveguide writing, light detection and ranging techniques, etc.

Although the first observations of MF in Kerr media have revealed an apparent competition between the random and deterministic beam breakup, experiments with femtosecond laser pulses imply that random nature of beam breakup can be indeed regularized. In recent years, a remarkable progress towards a controlled beam breakup into multiple filaments has been achieved. Ma- jority of the methods rely upon the modifications of the input beam parameters, e.g. amplitude and phase. Controlled MF patterns were generated by means of reshaping an input beam profile by a slit or diaphragm, controlled phase aberrations [4], and phase masks [5], introducing periodic amplitude modulation by the use of meshes and grids [6,7], or controllable focusing conditions by means of a deformable mirror [8]. Another way towards controlled MF exploits launching an elliptical beam and has proved to be successful in overcoming random small-scale filamentation. Beam breakup starts evolving along the major axis and ends up with stable and entirely predictable MF patterns. To this regard, reproducible MF patterns by slightly elliptical beams had been observed in various nonlinear media: water [9], air [10], BK7 glass [11], fused silica [12], and carbon disulfide [13], all revealing the universality of the deterministic breakup process.

The abovementioned modifications to the input beam lead not only to the formation of controllable MF patterns with predictable number of filaments in a desired way, but also significantly improve the beam pointing stability $[4,10]$. Most importantly, mutual coherence between filaments created by the same laser pulse was first suggested by [14] and later verified by means of interferometric measurements [15]. High coherence between and within the individual filaments promises many challenging applications in generation of carrier envelope phase-locked few-cycle pulses and 
frequency combs for metrology and precision spectroscopy.

In this paper we provide an experimental evidence of highly elliptic beam (light stripe) breakup into selforganized array of white-light filaments in water and in fused silica. Our data suggests that despite the breakup process being initially driven by noise, it results in highly deterministic positions, spacing, and number of individual filaments.

Experiments were carried out by launching $200 \mathrm{fs}$ $527 \mathrm{~nm}$ pulses from a chirped-pulse amplification technique based $\mathrm{Nd}$ : glass laser system (Twinkle, Light Conversion Ltd., Vilnius, Lithuania) running at $33 \mathrm{~Hz}$ repetition rate with a frequency-doubling compressor [16]. Spatially filtered Gaussian beam was focused by means of a cylindrical lens $\left(f_{x}=+500 \mathrm{~mm}\right.$ and $f_{y}=$ $\infty)$ and resulted in $90 \mu \mathrm{m} \times 1.2 \mathrm{~mm}$ full width at half maximum (FWHM) light stripe with ellipticity $e \approx 13$ at the input face of the sample as shown in Fig. 1(at $0 \mathrm{~mm}$ ). In the first experiment the sample we used was a syringe-shaped water cell of variable length, while in the second experiment it was a $41 \mathrm{~mm}$ long fused silica slab. The output face of the sample was imaged onto a CCD camera (COHU, pixel dimension $9.9 \mu \mathrm{m}, 10$ bit dynamic range, frame grabber from Spiricon Inc.) by means of an $f=+45 \mathrm{~mm}$ achromatic objective with $4 \times$ magnification. In order to get a closer insight into beam breakup dynamics, a complementary imaging by $10 \times$ magnification of the central beam part was used. The incident power was adjusted by means of a halfwave plate and a polarizer within wide margins, so as to excite the beam breakup into multiple filaments within the samples.

In the first series of experiments we recorded the self-focusing dynamics of highly elliptical beam in water versus propagation distance. The details are shown in Fig. 1. We have chosen the input beam energy $E_{\text {in }}=29 \mu \mathrm{J}$ that corresponds to the input power of $125 P_{\mathrm{cr}}, P_{\mathrm{cr}}=1.15 \mathrm{MW}$. In the first $15 \mathrm{~mm}$ of propagation we observe a gradual one-dimensional focusing of the beam along the minor axis of an ellipse accompanied by a growth of noise modulation, as seen from beam cross-sections depicted in Fig. 2. After $20 \mathrm{~mm}$ of propagation the most intense part of the elliptic beam breaks up into several well-pronounced light filaments of $\sim 20 \mu \mathrm{m}$ FWHM width each, accompanied by conical emission and white-light generation and surrounded by a characteristic ring structure, which closely resemble the general features observed in the single filament dynamics [17]. The breakup area extends further with propagation, resulting in equidistantly located peaks -

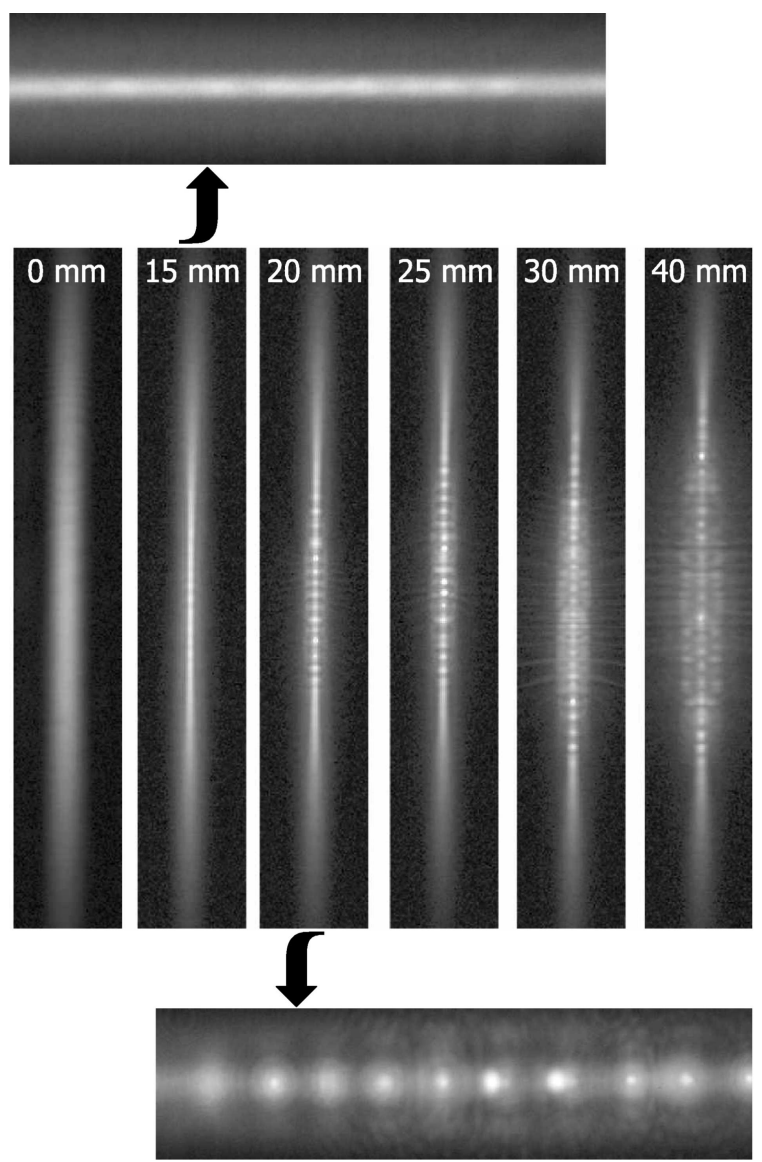

Fig. 1. Breakup dynamics of highly elliptical beam versus propagation distance in water cell. Dimension of a single image is $370 \mu \mathrm{m} \times 3 \mathrm{~mm}$. Insets show the magnified portion of the central part with dimension $150 \times 650 \mu \mathrm{m}^{2}$.

an array of white-light filaments. Our data suggests that the initial propagation stage of highly-elliptic beams is essentially one-dimensional self-focusing. During that propagation stage, certain noise frequencies grow, leading to a transverse instability, which ultimately results in beam breakup into an array of filaments along the major axis of an ellipse. The period of the filaments was found to be $55 \mu \mathrm{m}$ and remained fairly constant. With further propagation, interference between the conical parts of the neighbouring filaments gives rise to more complicated two-dimensional structures, which first appear as weak secondary stripes parallel to the main beam and evolve into distinct spots.

We observed that particular positions of the individual filaments in water slightly varied from shot to shot within the range of $20 \mu \mathrm{m}$. In order to show that this instability of MF pattern is due to water turbulence and tiny impurities such as dust grains floating inside the open water cell, and not due to shot-to-shot fluctuations in the input beam profile, we tested the stability of the position of an individual filament by generating 


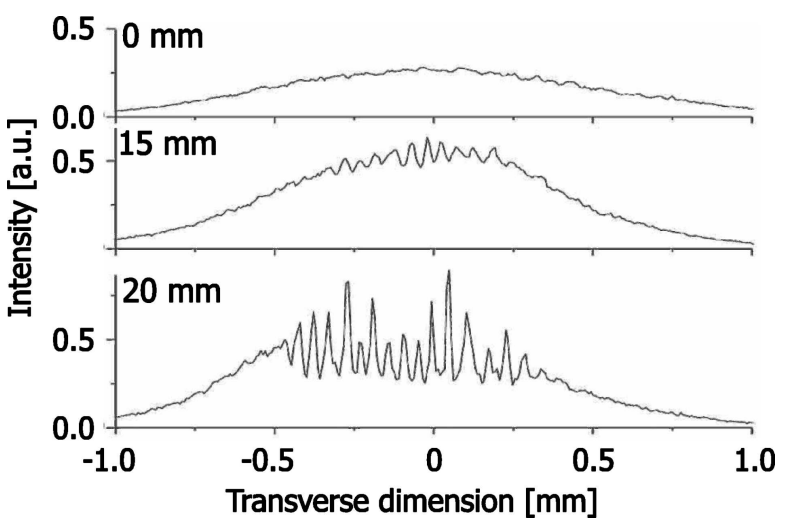

Fig. 2. Central cross-section of the beam showing the birth of a filament array.

a filament array in the $41 \mathrm{~mm}$ long fused silica slab. Instead of changing the sample length, we varied the input beam energy from 15 to $32 \mu \mathrm{J}$, what corresponds to power range of 80-170 $P_{\mathrm{cr}}$, with $P_{\mathrm{cr}}$ being $0.9 \mathrm{MW}$ for fused silica. The results are presented in Fig. 3. In this case the filaments were precisely located and did not change their position from one laser shot to another. The observed stability in position suggests that high ellipticity dominates the noise in determining the overall MF pattern. We also note an excellent high shot-toshot energy reproducibility and high pointing stability of the laser beam, which is achieved by a feedback system and computer controlled operation [16].

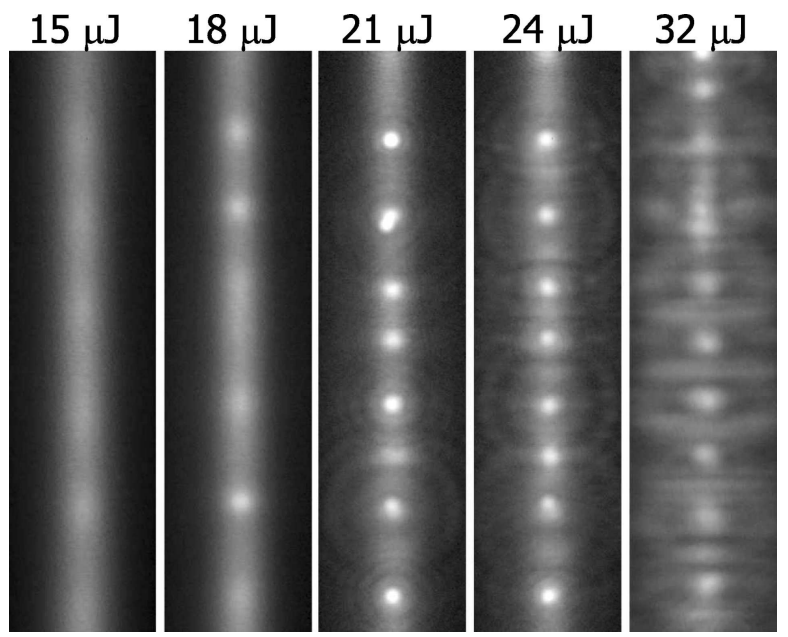

Fig. 3. Beam breakup and generation of the filament array in $41 \mathrm{~mm}$ long fused silica sample as a function of incident energy.

Stable positions of the filaments allowed for the more precise observations of how exactly the filaments appear. It is evident that initial filaments form from small perturbations (seen as brighter regions in the light stripe) in the self-focusing beam that start to be visible with $15 \mu \mathrm{J}$ input pulses. Further these perturbations evolve into nuclei, which finally give rise to individual filaments. Another interesting observation of the breakup process points to generation of some of the filaments at the intersections of individual rings. These filaments appear further in terms of propagation distance, or at higher incident power, and fill the gaps where initial noise-driven nuclei are absent (compare the patterns in Fig. 3 recorded at 18 and $21 \mu \mathrm{J}$ ).

Summarizing the experimental observations, we found that breakup of highly elliptical beams into arrays of filaments is deterministic, with each peak in the MF pattern being highly reproducible in position. At low input power the breakup dynamics is essentially one-dimensional along the major axis of the ellipse, whereas with increase of either power or propagation length, the dynamics become two-dimensional, owing to conical structure of individual filaments. And finally, assuming recent investigations on nonlinear $\mathrm{X}$-wave generation through filamentation [18], it is expected that multiple filamentation opens a direct route to generate an array of coherent X-pulses, which can be useful for fast and inexpensive way for modifications of transparent bulk materials.

\section{References}

[1] R.R. Alfano, The Supercontinuum Laser Source, 2nd ed. (Springer, New York, 2006).

[2] S.L. Chin, S.A. Hosseini, W. Liu, Q. Luo, F. Theberge, A. Aközbek, A. Becker, V.P. Kandidov, O.G. Kosareva, and H. Schroeder, The propagation of powerful femtosecond laser pulses in optical media: Physics, applications, and new challenges, Can. J. Phys. 83, 863-905 (2005).

[3] M. Mlejnek, M. Kolesik, J.V. Moloney, and E.M. Wright, Optically turbulent femtosecond light guide in air, Phys. Rev. Lett. 83, 2938-2941 (1999).

[4] G. Méchain, A. Couairon, M. Franco, B. Prade, and A. Mysyrowicz, Organizing multiple femtosecond filaments in air, Phys. Rev. Lett. 93, 035003 (2004).

[5] T. Pfeifer, L. Gallmann, M.J. Abel, D.M. Neumark, and S.R. Leone, Circular phase mask for control and stabilization of single optical filaments, Opt. Lett. 31, 2326-2328 (2006).

[6] V.P. Kandidov, N. Aközbek, M. Scalora, O.G. Kosareva, A.V. Nyakk, Q. Luo, S.A. Hosseini, and S.L. Chin, Towards a control of multiple filamentation by spatial regularization of a high-power femtosecond laser pulse, Appl. Phys. B 80, 267-275 (2005).

[7] H. Schroeder, J. Liu, and S.L. Chin, From random to controlled small-scale filamentation in water, Opt. Express 12, 4768-4774 (2004). 
[8] Z. Jin, J. Zhang, M.H. Lu, Y.T. Li, Z.H. Wang, Z.Y. Wei, X.H. Yuan, and W. Yu, Control of filamentation induced by femtosecond laser pulses propagating in air, Opt. Express 13, 10424-10430 (2005).

[9] A. Dubietis, G. Tamošauskas, G. Fibich, and B. Ilan, Multiple filamentation induced by input-beam ellipticity, Opt. Lett. 29, 1126-1128 (2004).

[10] G. Fibich, S. Eisenmann, B. Ilan, and A. Ziegler, Control of multiple filamentation in air, Opt. Lett. 29, 1772-1174 (2004).

[11] T.D. Grow and A.L. Gaeta, Dependence of multiple filamentation on beam ellipticity, Opt. Express 13, 45944599 (2005).

[12] V. Kudriašov, E. Gaižauskas, and V. Sirutkaitis, Beam transformation and permanent modification in fused silica induced by femtosecond filaments, J. Opt. Soc. Am. B 22, 2619-2627 (2005).

[13] M. Centurion, Y. Pu, and D. Psaltis, Self-organization of spatial solitons, Opt. Express 13, 6202-6211 (2005).

[14] S.L. Chin, S. Petit, W. Liu, A. Iwasaki, M.-C. Nadeau,
V.P. Kandidov, O.G. Kosareva, and K.Yu. Andrianov, Interference of transverse rings in multiflamentation of powerful femtosecond laser pulses in air, Opt. Commun. 210, 329-341 (2002).

[15] K. Cook, A.K. Kar, and R.A. Lamb, White-light supercontinuum interference of self-focused filaments in water, Appl. Phys. Lett. 83, 3861-3863 (2003).

[16] R. Danielius, A. Dubietis, A. Juozapavicius, A. Piskarskas, G. Tamosauskas, and A. Varanavicius, A versatile ultrashort laser system and its potential applications, Proc. SPIE 5137, 10-17 (2003).

[17] A. Dubietis, A. Couairon, E. Kučinskas, G. Tamošauskas, G. Gaižauskas, D. Faccio, and P. Di Trapani, Measurement and calculation of nonlinear absorption associated with femtosecond filaments in water, Appl. Phys. B 84, 439-446 (2006).

[18] A. Couairon, E. Gaižauskas, D. Faccio, A. Dubietis, and P. Di Trapani, Nonlinear X-wave formation by femtosecond filamentation in Kerr media, Phys. Rev. E 73, 016608 (2006).

\title{
PERIODINIU DAUGIAGIJŲ DARINIU GENERAVIMAS ELIPSINIAIS ŠVIESOS PLUOŠTAIS
}

\author{
A. Dubietis, E. Kučinskas, G. Tamošauskas \\ Vilniaus universitetas, Vilnius, Lietuva
}

\section{Santrauka}

Eksperimentiškai ištirtas elipsinių šviesos pluoštų fokusavimasis ir daugiagijų dariniu generacija kondensuotose terpèse su Kerro netiesiškumu (vandenyje ir lydytame kvarce). Parodyta, kad labai elipsinis lazerio pluoštas dèl saviveikos pradžioje transformuojasi i vienmati periodinį ir gerai atsikartojantị daugiagiji darinị. Atskirų šviesos gijų tarpusavio sąveika vèliau formuoja sudètingesnius dvimačius šviesos darinius. 